\title{
Oxidative stress and acid-base balance during the transition period of neonatal Holstein calves submitted to different calving times and obstetric assistance
}

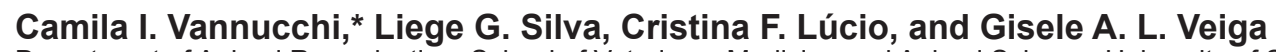

Department of Animal Reproduction, School of Veterinary Medicine and Animal Science, University of São Paulo, São Paulo, SP, Brazil 05508-270

\section{ABSTRACT}

During the neonatal period, constant adaptations to the extrauterine environment are required. These adaptations are made impossible or hindered when unexpected obstetrical events take place. This study aimed to identify clinical changes of vitality, metabolic and acid-base balance, and oxidative stress of newborn calves born to assisted dams that experienced different durations of calving. A prospective and observational study was conducted with 44 Holstein calves allocated to 3 groups according to the duration of calving: $2 \mathrm{~h}$ (n $=16), 2-4 \mathrm{~h}(\mathrm{n}=16)$, and $>4 \mathrm{~h}(\mathrm{n}=12)$, and to 2 subgroups: spontaneous calving $(\mathrm{n}=22)$ and assisted calving $(\mathrm{n}=22)$. We observed that obstetric assistance was beneficial when calving lasted more than $4 \mathrm{~h}$, because $100 \%$ of assisted calves had a high Apgar score $(\geq 7)$ at 5 min, similar to that of spontaneously born calves after $2 \mathrm{~h}$ of calving. Rectal temperature of all calves remained within normal values, albeit with a reduction at 20 min of life. Calves born after a calving time $>4 \mathrm{~h}$ had the highest rectal temperatures, especially those that required obstetrical assistance. There was a progressive increase in blood oxygenation with time, but calves in the $>4 \mathrm{~h}$ group showed the highest partial pressure of carbon dioxide at birth, whereas calves in the $2 \mathrm{~h}$ and $2-4 \mathrm{~h}$ groups had lower values. A decrease in partial pressure of $\mathrm{CO}_{2}$ was observed at $120 \mathrm{~min}$ in the $2-4 \mathrm{~h}$ and $>4 \mathrm{~h}$ groups. In the $2-4 \mathrm{~h}$ group, calves with obstetrical assistance had higher oxidative stress (measured as thiobarbituric acid reactive substances, TBARS) at 120 min of life compared with that at birth. In spontaneously born calves, TBARS increased only after $240 \mathrm{~min}$. In the $>4 \mathrm{~h}$ group, TBARS increased progressively with time, regardless of obstetrical subgroup. Calves born spontaneously within the $2 \mathrm{~h}$ group had higher TBARS values at birth than calves in the

Received March 16, 2018.

Accepted October 30, 2018.

*Corresponding author: cacavann@usp.br
$>4 \mathrm{~h}$ group with obstetrical assistance. Calves in the $>4 \mathrm{~h}$ group showed higher levels of glutathione peroxidase (an antioxidant enzyme) at birth than those in the remaining groups. Glutathione peroxidase decreased at $120 \mathrm{~min}$ in the $>4 \mathrm{~h}$ group and at $240 \mathrm{~min}$ for the $2 \mathrm{~h}$ and $2-4 \mathrm{~h}$ groups. In conclusion, obstetric assistance did not improve neonatal vitality and blood oxygenation when calving lasted less than $2 \mathrm{~h}$. Calves born after $2 \mathrm{~h}$ of calving showed decreased vitality, hypercapnia, hypoxemia, and increased antioxidant status (glutathione peroxidase).

Key words: antioxidant, prolonged calving, acid-base imbalance, Apgar score

\section{INTRODUCTION}

During the neonatal period, constant adaptations to the extrauterine environment are required. These adaptations are made impossible or hindered when unexpected obstetrical events take place. For example, prolonged or intermittent asphyxia in utero results in life-threatening, decreased neonatal vitality and a reduction in the neonate's ability to adapt to extrauterine life. In addition, under adverse environmental conditions, and especially in weakened calves, appropriate supervision and assistance are extremely important during the neonatal period. The quality and type of assistance during calving, notably in regards to frequent supervision and obstetrical intervention, are of utmost importance concerning the risks of perinatal mortality (Mee et al., 2014). Hence, proper medical management during and after calving is a determinant factor for reducing neonatal mortality and stillbirths. Neonatal mortality rates have changed minimally over the last few years, evidencing a technical failure to deal with strategies that can prevent perinatal losses (Uystepruyst et al., 2002; Mee, 2011).

Dystocia accounts for $40 \%$ of calf mortality during the first $24 \mathrm{~h}$ of life (Patterson et al., 1987) and it reduces the survival rate to only $85 \%$ until weaning (Arthur et al., 2000). Calves born following dystocia 
have 2.6 times less vitality at birth and they are 13 times more likely to die before weaning (Riley et al., 2004). In addition, prolonged calving $(>2 \mathrm{~h})$ reduces calf survival: the stillbirth rate increases by $30 \%$ for every additional hour after the appearance of fetal hooves (Mee et al., 2014). A longer duration of calving is associated with lower calf venous blood $\mathrm{pH}$ and reduced weight gain (Murray et al., 2015). However, the protocol for obstetrical assistance may vary according to the management system, the technical knowledge of the workers, and prioritization of individual cows or calves. For example, calf vitality at birth is reported to be lower in premature assisted calving compared with assisted calving with appropriately timed obstetrical assistance or unassisted calving (Kovács et al., 2016). Hence, studies focused on comparing the types of obstetrical assistance are required to determine their effects in neonatal survival.

The main alterations throughout the neonatal period originate from fetal hypoxia due to intense and prolonged uterine contractions causing disruptions of the uterine and placental circulation and umbilical cord disorders (Siristatidis et al., 2004). The strength of contractions and the pressure on the pelvic area create an environment of prolonged fetal acidosis, which result from anaerobic metabolism (Norén et al., 2003). Fetal and neonatal blood acidosis is one of the most important consequences of dystocia. Also, prolonged labor may promote early rupture of the umbilical cord, diminishing fetal oxygenation and therefore causing asphyxia and respiratory acidosis (Murray and Leslie, 2013). Prolonged hypoxia leads to changes in circulating concentration of blood glucose and cortisol; it reduces the thermoregulation metabolism and causes damage to central and sympathetic nervous systems of newborns (Bellows and Lammoglia, 2000). If long lasting, fetal hypoxia leads to diminished blood perfusion to the placenta and, consequently, increased reactive oxygen species (ROS), compromising neonatal viability (Frosali et al., 2004). On the other hand, fetal acidosis and hypoxia, as well as oxidative stress, can be avoided through supporting assistance such as manual obstetrical correction, which can reestablish neonatal respiratory, cardiovascular, thermoregulatory, and metabolic functions (Rice, 1994). Therefore, we hypothesize that calving that lasts longer than $2 \mathrm{~h}$ and obstetric assistance hinder neonatal adaptation to the extrauterine transition period and can cause deleterious oxidative stress that has to be additionally scavenged by neonatal antioxidant mechanisms.

Therefore, in this study, we aimed to identify clinical changes in vitality, metabolic and acid-base balance, and oxidative stress of newborn calves born with the influence of different durations of calving and obstetric assistance.

\section{MATERIALS AND METHODS}

The current study was approved by the Bioethics Committee of the School of Veterinary Medicine and Animal Science, University of São Paulo, under the protocol number 1778/2009.

\section{Animals and Experimental Groups}

As described in detail previously, using the same study population (Vannucchi et al., 2017, 2018), we conducted a prospective and observational study in a single dairy herd with high-milk-producing Holstein cows and heifers of BCS between 2.5 and 3.5. The local air temperature and humidity ranged from 17.6 to $23.5^{\circ} \mathrm{C}$ and from 68.3 to $79.7 \%$, respectively, with an average wind speed ranging from 9 to $11 \mathrm{~km} / \mathrm{h}$. The dams were fed a TMR (corn silage and Tifton hay as forage, and a corn, soybean, and cottonseed meal-based concentrate). Animals were provided with ad libitum access to water.

Preparturient heifers and cows (the number of heifers and cows was equally distributed within groups) were housed individually in a covered maternity set approximately $1 \mathrm{wk}$ before they were due to calve. The experimental groups were determined according to the duration of the expulsive phase of calving, defined as the time from the fetal membrane rupture (allantois) until complete expulsion of the calf. Therefore, cows were allowed to calve for the following periods (groups):

(1) $\mathbf{2} \mathbf{h}(\mathrm{n}=16 ; \mathrm{n}=8$ cows and $\mathrm{n}=8$ heifers $)$ : expulsive phase of calving with duration $<2 \mathrm{~h}$. This group was additionally subdivided into a spontaneous calving subgroup (without external obstetrical assistance; $\mathrm{n}=8$ ) and assisted calving subgroup (external obstetrical assistance was performed at the time equivalent to when the previous female calved in the spontaneous calving subgroup; $\mathrm{n}=8$ ).

(2) $\mathbf{2}-\mathbf{4} \mathbf{h}(\mathrm{n}=16 ; \mathrm{n}=8$ cows and $\mathrm{n}=8$ heifers $)$ : expulsive phase of calving with intermediate duration of 2 to $4 \mathrm{~h}$. This group was composed of 8 primiparous and 8 multiparous females. This group was additionally subdivided into a spontaneous calving subgroup $(\mathrm{n}=8)$ and assisted calving subgroup $(\mathrm{n}=8)$.

(3) $>4 \mathbf{h}(\mathrm{n}=12 ; \mathrm{n}=6$ cows and $\mathrm{n}=6$ heifers $)$ : expulsive phase of calving lasting longer than 4 h. This group was composed of 6 primiparous 
and 6 multiparous females. This group was additionally subdivided into a spontaneous calving sub-group $(\mathrm{n}=6)$ and an assisted calving subgroup $(\mathrm{n}=6)$.

To ensure the appropriate sample size, an analysis was conducted with the SAS Power and Sample Size 12 (SAS Institute Inc., Cary, NC). A retrospective analysis of serum concentrations of superoxide dismutase (SOD) and thiobarbituric acid reactive substances (TBARS) indicated power of 0.81 and 0.85 , respectively, which is considered acceptable statistical power $(\geq 0.8)$. Hence, at least 8 females per calving-time group was sufficient to demonstrate significant differences in the data. For each cow that presented spontaneous labor (spontaneous calving subgroups), the next cow that reached the same calving duration was subjected to obstetric assistance. Thus, we exactly matched the time elapsed from the rupture of fetal membranes for both experimental subgroups (spontaneous and assisted). Forced fetal extraction was considered mild to moderate with the aid of obstetric chains, with tractive force performed by 1 or 2 individuals, respectively.

Calving was observed from the preparatory phase until the complete expulsion of the calf. Cows were subjected to external and internal obstetric examination before any manual obstetric assistance. The birth canal was assessed through vaginal palpation, taking into consideration calf malpresentation and overall dilation of the birth canal. Malpresentation of the calf, twins, or uterine inertia were excluded from the experiment. To ensure that the birth weight of the calves was not a determinant factor for the duration of calving, calves were weighed soon after birth. The mean birth weight $( \pm \mathrm{SEM})$ in each experimental group was as follow: $35.42 \mathrm{~kg} \pm 1.66$ for the $2 \mathrm{~h}$ group, $38.85 \mathrm{~kg} \pm 1.17$ for the $2-4 \mathrm{~h}$ group, and $39.36 \mathrm{~kg} \pm 2.14$ for the $>4 \mathrm{~h}$ group, with no significant statistical difference among groups.

\section{Analysis of Neonatal Vitality and Arterial Acid-Base Parameters}

Neonatal vitality was verified through an Apgar score previously described for bovines (Vannucchi et al., 2015b). For statistical analysis purposes, the Apgar score was transformed to a binomial variable: percentage of calves with low Apgar score $(<7)$ and percentage of calves with high Apgar score $(\geq 7)$, according to the standardization of Vannucchi et al. (2015b). Analysis of neonatal vitality was conducted at birth (immediately after expulsion of the calf) and 5, 10, 20, and $30 \mathrm{~min}$ later. Rectal temperature was measured at birth, 5 min, every $10 \mathrm{~min}$ until $90 \mathrm{~min}$, and at 120,180 , and 240 min of life.

At birth and 120 and $240 \mathrm{~min}$ thereafter, 0.5 to $1 \mathrm{~mL}$ of arterial blood was collected by saphenous, femoral, or coccygeal artery puncture, depending on the accessibility of the blood vessel. Sampling a peripheral or a central artery for the assessment of calves acid-base balance is considered suitable (Nagy et al., 2001). Whenever the collection of blood samples from the coccygeal artery was not possible (e.g., low blood pressure), arterial blood was collected from the saphenous or femoral artery. Care was taken to avoid collecting a sample of mixed venous and arterial blood of the coccygeal artery: the appearance of the whole blood (bright red color) and flow rate were used to assure an arterial origin. Although sampling the coccygeal artery can render an admixture of arterial and venous blood, mixed venous blood can be an indicator of acid-base changes; and blood from any venous site will accurately reflect the acid-base status (Ilkiw et al., 1991). Collection of blood from the coccygeal artery for measurement of blood gases and $\mathrm{pH}$ was previously validated for calves (Gunes and Atalan, 2006). Blood sample was immediately tested using the i-STAT system (Abbott Laboratories, Chicago, IL) for $\mathrm{pH}$, partial pressure of $\mathrm{CO}_{2}\left(\mathbf{p C O}_{2} ; \mathrm{mmHg}\right)$, partial pressure of oxygen $\left(\mathrm{pO}_{2} ; \mathrm{mmHg}\right)$, bicarbonate $\left(\mathrm{HCO}_{3}{ }^{-}\right)$concentration $(\mathrm{mmol} / \mathrm{L})$, base excess $(\mathbf{B E} ; \mathrm{mmol} / \mathrm{L})$, total $\mathrm{CO}_{2}\left(\mathbf{T C O} \mathbf{C O}_{2} ; \mathrm{mmol} / \mathrm{L}\right)$, oxygen saturation $\left(\mathbf{s O}_{2} ; \%\right)$, $\mathrm{Na}^{+}$concentration $(\mathrm{mmol} / \mathrm{L})$, and $\mathrm{K}^{+}$concentration $(\mathrm{mmol} / \mathrm{L})$. The values were corrected according to the animal's rectal temperature.

\section{Analysis of Blood Glucose Concentration and Serum Oxidative Stress}

Oxidative stress and blood glucose analyses were conducted at birth and 120 and 240 min thereafter. Through puncturing of jugular veins, $3 \mathrm{~mL}$ of blood was collected from the neonates, and put into sterile tubes with gel and without anticoagulants (to obtain blood serum) or directly subjected to glucometry (Accu-Chek, Roche Diabetes Care, Indianapolis, IN) to determine blood glucose concentration $(\mathrm{mmol} / \mathrm{L})$. The tubes with blood were centrifuged after clotting at $1,500 \times g$ for $10 \mathrm{~min}$. The obtained serum was divided into plastic microtubes and stored in a freezer at $-20^{\circ} \mathrm{C}$ until processing.

Considering oxidative stress variables, the concentrations of the antioxidant enzymes glutathione peroxidase $(\mathbf{G P x})$ and SOD, and the oxidative stress marker TBARS were determined and previously validated using a standard curve for all animal species. We in- 
vestigated serum concentration of SOD and GPx; both enzymes catalyze the complete chain reaction in which superoxide anion, the first produced ROS, is sequentially converted into water (Vannucchi et al., 2015a). Extracellular GPx, which is found in serum, is believed to play an important role in protecting extracellular fluid components and cell surfaces against peroxidemediated damage (Yamamoto and Takahashi, 1993). Malondialdehyde (MDA), a product of lipid peroxidation, may be deleterious, triggering an oxidative chain reaction. The measurement of TBARS is a proxy for MDA concentration (Vannucchi et al., 2015a).

Serum GPx activity was measured by spectrophotometer (Ultrospec 3300 Pro, Amersham Biosciences/GE Healthcare, Amersham, UK) at a wavelength of $340 \mathrm{~nm}$ at $37^{\circ} \mathrm{C}$ for $100 \mathrm{~min}$ (Nichi et al., 2007), followed by a reaction containing NADPH $(0.12 \mathrm{mM}, 1 \mathrm{~mL})$, oxidized glutathione $(0.25 \mathrm{U} / \mathrm{mL}, 20 \mathrm{~mL})$ and glutathione $(1 \mathrm{~m} M, 100 \mathrm{~mL})$. The results were expressed in units per milliliter.

The determination of serum SOD activity was performed according Flohé and Ötting (1984). The assay was performed in a spectrophotometer (Ultrospec 3300 Pro, Amersham Biosciences/GE Healthcare) at $550 \mathrm{~nm}$ and $25^{\circ} \mathrm{C}$ in a reaction medium containing cytochrome C $(1 \mu M)$, xanthine $(50 M)$, EDTA $(100 \mu M)$, and sodium phosphate buffer $(50 \mu M, \mathrm{pH} 7.8)$. The results were expressed in units per milliliter.

Analysis of TBARS was made in accordance with a protocol first described by Ohkawa et al. (1979). To precipitate proteins, $200 \mu \mathrm{L}$ of serum and $400 \mu \mathrm{L}$ of a $10 \%$ solution ( $\mathrm{vol} / \mathrm{vol}$ ) of trichloroacetic acid ( $10 \%$ ) were mixed and centrifuged $(18,000 \times g$ for $15 \mathrm{~min}$ at $\left.15^{\circ} \mathrm{C}\right)$. After centrifugation, $500 \mu \mathrm{L}$ of the supernatant and $500 \mu \mathrm{L}$ of $1 \%$ (vol/vol) thiobarbituric acid (1\%) in $0.05 \mathrm{~N} \mathrm{NaOH}$ in glass tubes were placed into a boiling water bath $\left(100^{\circ} \mathrm{C}\right)$ for $10 \mathrm{~min}$, and subsequently cooled in an ice bath $\left(0^{\circ} \mathrm{C}\right)$ to stop the chemical reaction. Then, TBARS were quantified by spectrophotometry at a wavelength of $532 \mathrm{~nm}$ (Ultrospec 3300 Pro, Amersham Biosciences/GE Healthcare). The results were compared with a standard curve previously prepared with a solution of MDA, using a value of $1.56 \times 10^{5}$ $M^{-1} \cdot \mathrm{cm}^{-1}$ as the MDA extinction coefficient (Buege and Aust, 1978). The lipid-peroxidation index was expressed in nanograms of TBARS per milliliter of serum, and data were log-transformed for statistical analysis.

\section{Statistical Analysis}

The experimental design was a $3 \times 2$ factorial, considering 3 groups of calving time and 2 subgroups of obstetrical assistance. All data were evaluated us- ing SAS for Windows 9.3 (SAS Institute Inc., Cary, NC). Differences between treatments were analyzed using parametric and nonparametric tests, according to the residual normality (Gaussian distribution) and variance homogeneity. Whenever necessary, data were transformed to obey these statistical assumptions. If no significant interactions were observed, the effect of groups (calving duration) was analyzed merging all subgroups (obstetric assistance); conversely, subgroups were compared combining all groups. Otherwise, comparisons were performed taking into account both effects. Differences between treatments were analyzed using the Tukey test. A chi-squared test of independence was performed to analyze the relation between the percentage of calves with low Apgar score $(<7)$ and percentage of calves with high Apgar score $(\geq 7)$ within each experimental group. Whenever the expected percentage was $>25 \%$, Fisher's exact testing was used. The response variables were also submitted to Spearman correlation analysis.

Results are reported as untransformed means \pm standard errors of the means. For serum concentrations of TBARS, data were provided as mean and 95\% confidence interval. The significance level was set at $5 \%$; that is, $P$-values $<0.05$ were considered statistically significant.

\section{RESULTS}

We detected no significant interactions among calving groups, assistance subgroups, or evaluation times for $\mathrm{K}^{+}, \mathrm{Na}^{+}, \mathrm{BE}, \mathrm{pO}_{2}, \mathrm{pH}, \mathrm{TCO}_{2}$, or bicarbonate, blood glucose, GPx, or SOD concentrations. In regards to Apgar score and TBARS concentration, we detected a significant interaction among calving duration groups, assistance subgroups, and evaluation times. An interaction among groups and subgroups was found for rectal temperature. Only for $\mathrm{pCO}_{2}$ was a significant interaction among experimental groups and analysis times found.

Considering all groups $(2 \mathrm{~h}, 2-4 \mathrm{~h}$, and $>4 \mathrm{~h})$ and subgroups (spontaneous and assisted calving), we identified no correlation between fetal birth weight and calving duration $(\mathrm{r}=0.23 ; P=0.14)$. Accordingly, no influence of weight at birth was verified for spontaneous calving duration $(\mathrm{r}=0.04 ; P=0.85)$.

At $5 \mathrm{~min}$ of life, $100 \%$ of calves in the $2 \mathrm{~h}$ group without assistance and the $>4 \mathrm{~h}$ group with assistance (8/8 and 6/6, respectively) had high Apgar scores $(\geq 7)$, a greater percentage than found when the Apgar test was performed at birth $(P=0.007$ and $P=0.01$, respectively). The rectal temperature of all calves remained within normal values, albeit with a reduction 
A

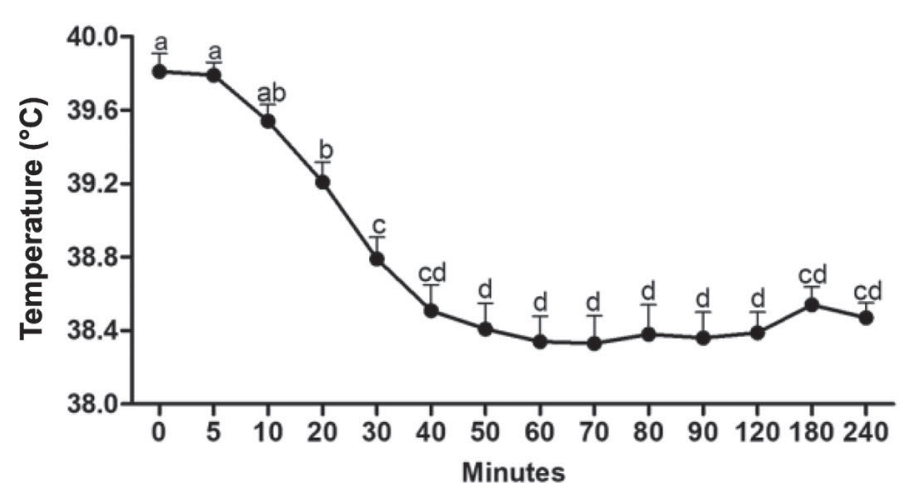

B

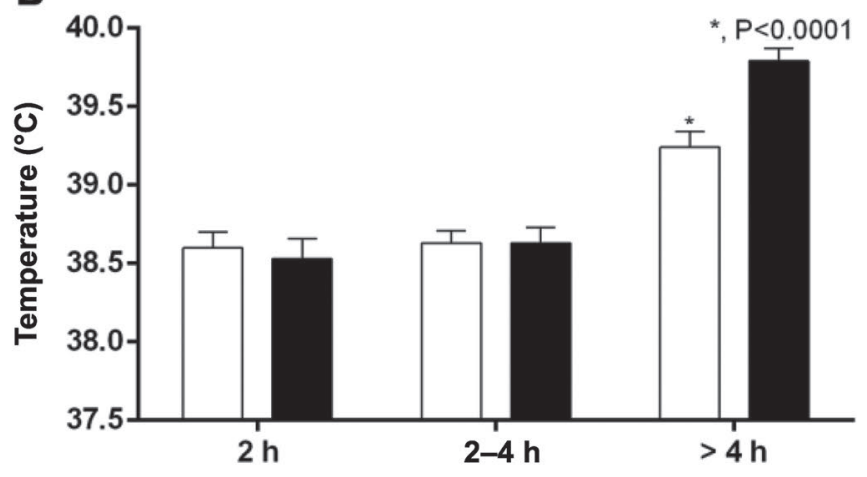

Figure 1. Rectal temperature $\left({ }^{\circ} \mathrm{C}\right)$ of calves $(\mathrm{A})$ over time and $(\mathrm{B})$ within each group $(2 \mathrm{~h}, 2-4 \mathrm{~h}$, and $>4 \mathrm{~h})$ and subgroup (spontaneous and assisted). Values with different letters $(\mathrm{a}, \mathrm{b})$ differ between evaluation times $(P<0.05)$. ${ }^{*}$ Difference between $>4 \mathrm{~h}$ group and the remaining groups $(P<0.05) ;{ }^{P<0.0001}$ Difference between spontaneous and assisted subgroups within the $>4 \mathrm{~h}$ group. Error bars indicate SE.

at $20 \mathrm{~min}$ of life $\left(39.2 \pm 0.1^{\circ} \mathrm{C}\right.$; Figure 1$)$. Stabilization of the rectal temperature was seen from $40 \mathrm{~min}$ onward. Comparing experimental groups, calves in the $>4 \mathrm{~h}$ group had the highest rectal temperature $(38.8$ $\left.\pm 1.6^{\circ} \mathrm{C}\right)$, especially those in the obstetrical assistance subgroup $\left(39.6 \pm 0.1^{\circ} \mathrm{C}\right.$; Figure 1$)$.

In regards to blood oxygenation, we observed a progressive increase over time, which occurred earlier for $\mathrm{sO}_{2}$ and in a linear manner for $\mathrm{pO}_{2}$ (Table 1). We detected increases in blood $\mathrm{pH}, \mathrm{BE}, \mathrm{TCO}_{2}$, and bicarbonate at 120 min of life (Table 1). The values of $\mathrm{pCO}_{2}$ at birth differed according to labor duration (Figure 2). The $>4$ h group had the highest $\mathrm{pCO}_{2}$ values at birth, whereas calves in the $2 \mathrm{~h}$ and $2-4 \mathrm{~h}$ groups had lower values; a decrease in $\mathrm{pCO}_{2}$ was observed at $120 \mathrm{~min}$ in the $2-4 \mathrm{~h}$ and $>4 \mathrm{~h}$ groups (Figure 2). For blood $\mathrm{pH}, \mathrm{pO}_{2}$, bicarbonate, $\mathrm{TCO}_{2}, \mathrm{BE}, \mathrm{Na}^{+}$, and $\mathrm{K}^{+}$, no differences were noted among experimental groups and subgroups.

Blood glucose analysis during the experimental period showed a progressive decrease, although not significant, in glucose over time $(3.71 \pm 0.33,3.48 \pm 0.31$, and $3.06 \pm 0.2 \mathrm{mmol} / \mathrm{L}$, respectively, at birth, 120 , and 240 min). Similarly, blood glucose did not differ among experimental groups and subgroups.

All calves born with obstetric assistance showed a progressive increase in oxidative stress (TBARS) toward 240 min of life (Table 2). For spontaneously born calves of the $2-4 \mathrm{~h}$ group, TBARS increased only after $240 \mathrm{~min}$. At $120 \mathrm{~min}$ of life, the $2-4 \mathrm{~h}$ group with obstetric assistance had higher TBARS values than the subgroup with spontaneous calving.

Concentrations of GPx were not different among experimental subgroups. However, at birth, calves in the
$>4 \mathrm{~h}$ group had higher GPx than calves in the other groups (Figure 3). The concentration of GPx decreased at $120 \mathrm{~min}$ in the $>4 \mathrm{~h}$ group and at $240 \mathrm{~min}$ in the $2 \mathrm{~h}$ and $2-4 \mathrm{~h}$ groups (Figure 3 ).

In regards to SOD determination, we observed no differences among groups ( 2 h group: $62.5 \pm 8.2 \mathrm{U} / \mathrm{mL}$; $2-4 \mathrm{~h}$ group: $57.4 \pm 7.5 \mathrm{U} / \mathrm{mL}$; $>4$ h group: $71.4 \pm$ $6.7 \mathrm{U} / \mathrm{mL}$ ), subgroups (spontaneous: $67.5 \pm 6.2 \mathrm{U} / \mathrm{mL}$ vs. assistance: $58.7 \pm 6.3 \mathrm{U} / \mathrm{mL}$ ), or evaluation times $(0$ min: $62.7 \pm 7.4 \mathrm{U} / \mathrm{mL} ; 120 \mathrm{~min}: 57.8 \pm 8.4 \mathrm{U} / \mathrm{mL}$; 240 min: $68.8 \pm 7.2 \mathrm{U} / \mathrm{mL})$.

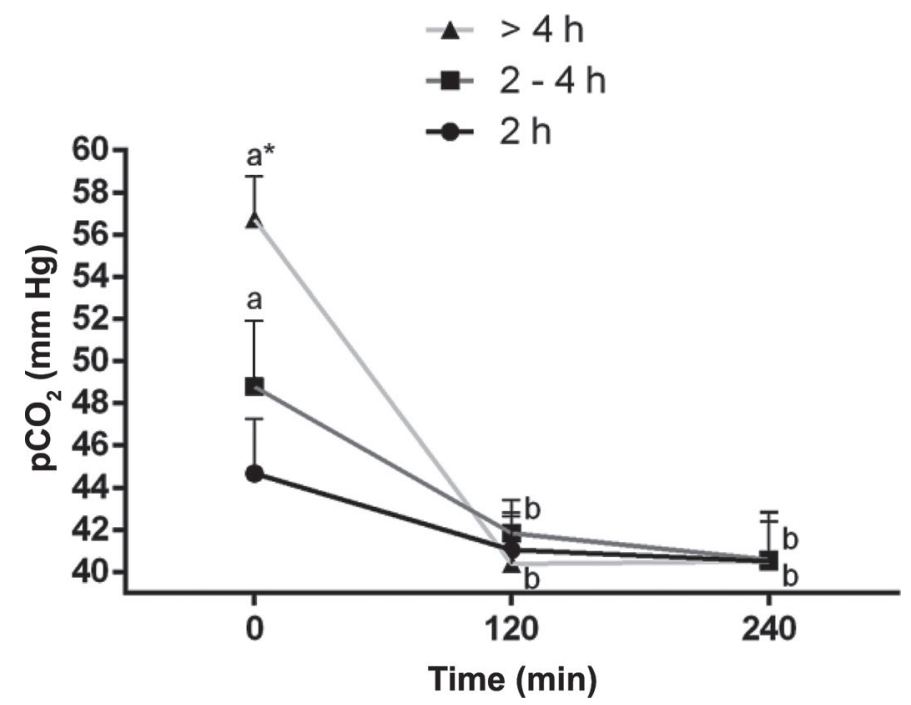

Figure 2. Blood partial pressure of carbon dioxide $\left(\mathrm{pCO}_{2} ; \mathrm{mmHg}\right)$ over time of calves in the $2 \mathrm{~h}, 2-4 \mathrm{~h}$, and $>4 \mathrm{~h}$ groups. Values with different letters $(\mathrm{a}, \mathrm{b})$ differ between evaluation times $(P<0.05)$. *Difference between $>4 \mathrm{~h}$ group and the remaining groups $(P<0.05)$. Error bars indicate SE. 
Table 1. Arterial blood gas values (means \pm SEM) of calves at birth (0 min) and 120 and 240 min after birth

\begin{tabular}{|c|c|c|c|}
\hline Variable $^{1}$ & $0 \min$ & $120 \min$ & $240 \min$ \\
\hline $\mathrm{pH}$ & $7.23 \pm 0.02^{\mathrm{b}}$ & $7.38 \pm 0.01^{\mathrm{a}}$ & $7.41 \pm 0.01^{\mathrm{a}}$ \\
\hline Bicarbonate $(\mathrm{mmol} / \mathrm{L})$ & $20.5 \pm 0.8^{\mathrm{b}}$ & $23.9 \pm 0.6^{\mathrm{a}}$ & $25.1 \pm 0.5^{\mathrm{a}}$ \\
\hline $\mathrm{TCO}_{2}(\mathrm{mmol} / \mathrm{L})$ & $21.9 \pm 0.8^{\mathrm{b}}$ & $25 \pm 0.6^{\mathrm{a}}$ & $26.2 \pm 0.6^{\mathrm{a}}$ \\
\hline Base excess $(\mathrm{mmol} / \mathrm{L})$ & $-5.4 \pm 1.1^{\mathrm{b}}$ & $-0.9 \pm 0.7^{\mathrm{a}}$ & $0.7 \pm 0.5^{\mathrm{a}}$ \\
\hline $\mathrm{pO}_{2}(\mathrm{mmHg})$ & $52.4 \pm 4.1^{\mathrm{b}}$ & $59.9 \pm 2.8^{\mathrm{ab}}$ & $68.9 \pm 3.3^{\mathrm{a}}$ \\
\hline $\mathrm{sO}_{2}(\%)$ & $64.7 \pm 2.4^{\mathrm{b}}$ & $84.4 \pm 1.3^{\mathrm{a}}$ & $88.8 \pm 1.1^{\mathrm{a}}$ \\
\hline $\mathrm{K}^{+-}(\mathrm{mmol} / \mathrm{L})$ & $4.8 \pm 0.2$ & $4.3 \pm 0.1$ & $4.8 \pm 0.5$ \\
\hline $\mathrm{Na}^{+}(\mathrm{mmol} / \mathrm{L})$ & $136.8 \pm 0.5$ & $136.9 \pm 0.4$ & $137.0 \pm 0.5$ \\
\hline
\end{tabular}

For spontaneously born calves from the $2 \mathrm{~h}$ group, there was a positive correlation between Apgar score and $\mathrm{BE}(\mathrm{r}=0.7 ; P=0.04)$ and $\mathrm{sO}_{2}(\mathrm{r}=0.7 ; P=$ $0.06)$; and between blood glucose concentration and GPx $(\mathrm{r}=0.6 ; P=0.001)$. In the $2 \mathrm{~h}$ group with assistance, we found positive correlations between Apgar score and bicarbonate concentration $(\mathrm{r}=0.7 ; P=0.04)$ and $\mathrm{TCO}_{2}(\mathrm{r}=0.7 ; P=0.06)$; between blood glucose concentration and GPx $(\mathrm{r}=0.5 ; P=0.006)$; and between TBARS concentration and $\mathrm{pH}(\mathrm{r}=0.6 ; P=$ 0.002 ). In the $2-4 \mathrm{~h}$ group under assistance, there were negative correlations between GPx and $\mathrm{BE}(\mathrm{r}=-0.5$; $P=0.02)$; GPx and bicarbonate $(\mathrm{r}=-0.5 ; P=0.01)$; GPx and $\mathrm{sO}_{2}(\mathrm{r}=-0.5 ; P=0.01)$; and $\mathrm{GPx}$ and $\mathrm{TCO}_{2}$ $(\mathrm{r}=-0.5 ; P=0.01)$. In spontaneously born calves with calving time $>4 \mathrm{~h}$, there were positive correlations between GPx and blood glucose concentration $(\mathrm{r}=0.7$; $P=0.002)$ and between GPx and $\mathrm{pCO}_{2}(\mathrm{r}=0.4 ; P=$ $0.07)$. Negative correlations were noted between rectal temperature and $\mathrm{pO}_{2}(\mathrm{r}=-0.5 ; P=0.02)$ and between rectal temperature and $\mathrm{sO}_{2}(\mathrm{r}=-0.7 ; P=0.001)$. For the $>4 \mathrm{~h}$ group with assistance, there were positive correlations between rectal temperature and GPx $(\mathrm{r}=$ 0.6; $P=0.005)$ and between TBARS and $\mathrm{pH}(\mathrm{r}=0.5$; $P=0.04)$. Negative correlations were noted between rectal temperature and $\mathrm{pO}_{2}(\mathrm{r}=-0.6 ; P=0.01)$, rectal temperature and $\mathrm{sO}_{2}(\mathrm{r}=-0.6 ; P=0.004)$; TBARS concentration and $\mathrm{pCO}_{2}(\mathrm{r}=-0.5 ; P=0.03)$; GPx concentration and $\mathrm{BE}(\mathrm{r}=-0.6 ; P=0.01)$; GPx and bicarbonate $(\mathrm{r}=-0.6 ; P=0.01)$; and GPx concentration and $\mathrm{TCO}_{2}(\mathrm{r}=-0.5 ; P=0.02)$.

\section{DISCUSSION}

In this experiment, both duration of calving and obstetric assistance resulted in differences in neonatal vitality at birth. Obstetric assistance was beneficial when calving lasted more than $4 \mathrm{~h}$ : $100 \%$ of these calves had a high Apgar score $(\geq 7)$ at 5 min, similar to spontaneously born calves in the $2 \mathrm{~h}$ group. In fact, labor duration may influence neonatal vitality, especially for calves born from calving longer than $2 \mathrm{~h}$ (Schafer and Arbeiter, 1995; Herfen and Bostedt, 1999). Fetal permanence in the pelvic canal for a prolonged period results in lower oxygenation, leading to the birth of low vitality calves. However, when obstetric assistance is provided in a prolonged calving $(>4 \mathrm{~h})$, vitality improved at $5 \mathrm{~min}$ after birth. In fact, Schuenemann et al. (2011) stated that manual assistance conducted 60 min after the expulsion stage reduced the proportion of stillborn calves from 15.5 to $6.5 \%$. Although no dystocia predictor, such as dam pelvic measurements, was used in the present experiment, we suggest that when prolonged calving time is predicted to occur, obstetric assistance should be considered.

Apgar score in the $2 \mathrm{~h}$ group was positively correlated with respiratory $\left(\mathrm{sO}_{2}\right.$ and $\left.\mathrm{TCO}_{2}\right)$ and metabolic (bicarbonate and $\mathrm{BE}$ ) variables of acid-base balance, regard-

Table 2. Mean [95\% CI] of serum concentration of thiobarbituric acid reactive substances (TBARS; ng $/ \mathrm{mL}$ ) over time of calves in 2, 2-4, and $>4 \mathrm{~h}$ groups and spontaneous and assisted subgroups

\begin{tabular}{|c|c|c|c|}
\hline Group & $0 \min$ & $120 \mathrm{~min}$ & $240 \mathrm{~min}$ \\
\hline $\begin{array}{l}\mathrm{h} \text { spontaneous } \\
2 \mathrm{~h} \text { assisted } \\
2-4 \mathrm{~h} \text { spontaneous } \\
2-4 \mathrm{~h} \text { assisted } \\
>4 \mathrm{~h} \text { spontaneous } \\
>4 \mathrm{~h} \text { assisted }\end{array}$ & $\begin{array}{l}352.7[228.9-476.4] \\
280.1[184.8-375.3]^{\mathrm{b}} \\
272.3[208.2-336.3]^{\mathrm{b}} \\
283.0[190.9-375.0]^{\mathrm{b}} \\
275.2[186.7-363.7]^{\mathrm{b}} \\
239.2[191.1-287.1]^{\mathrm{b}}\end{array}$ & $\begin{array}{l}340.1[216.8-463.3]^{\mathrm{AB}} \\
376.6[281.2-471.8]^{\mathrm{AB}, \mathrm{ab}} \\
248.8[199.8-297.8]^{\mathrm{B}, \mathrm{b}} \\
446.1[282.7-609.5]^{\mathrm{A}, \mathrm{a}} \\
346.5[247.9-445.0]^{\mathrm{AB}} \\
326.7[166.0-487.3]^{\mathrm{AB}, \mathrm{ab}}\end{array}$ & $\begin{array}{l}299.0[230.0-368.0] \\
431.9[268.9-594.8]^{\mathrm{a}} \\
438.1[267.2-609.0]^{\mathrm{a}} \\
323.5[255.7-391.2]^{\mathrm{ab}} \\
417.1[258.1-576.1] \\
388.5[300.2-476.7]^{\mathrm{a}}\end{array}$ \\
\hline
\end{tabular}




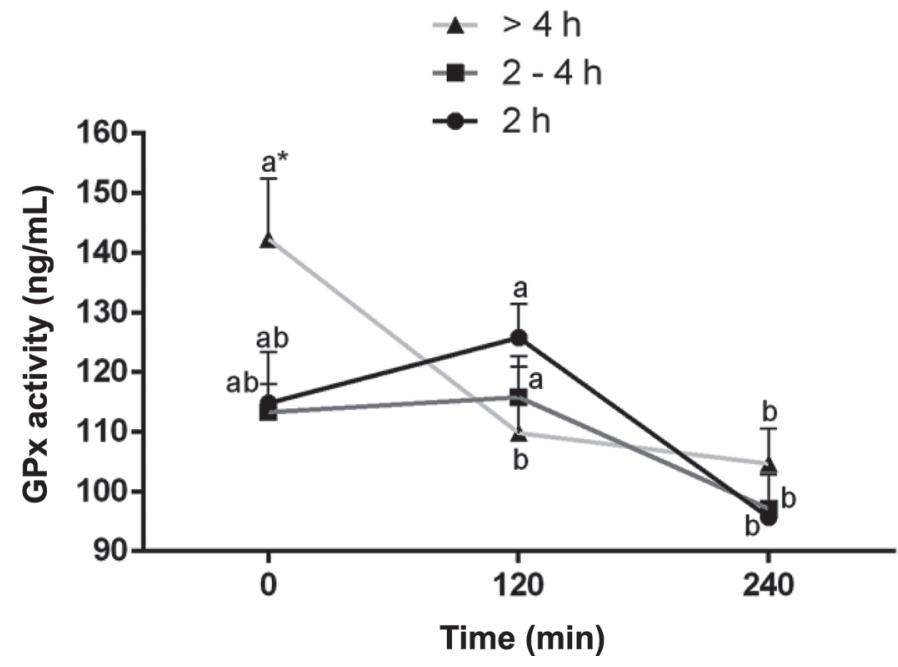

Figure 3. Serum activity of glutathione peroxidase (GPx; ng/mL) over time of calves in the $2 \mathrm{~h}, 2-4 \mathrm{~h}$, and $>4 \mathrm{~h}$ groups. Values with different letters $(\mathrm{a}, \mathrm{b})$ differ between evaluation times $(P<0.05)$. $*$ Difference between $>4 \mathrm{~h}$ group and the remaining groups $(P<0.05)$. Error bars indicate SE

less of obstetric assistance. This finding demonstrates the influence of fetal hypoxia and acidemia in vitality patterns of eutocic calves. In fact, we observed that calving duration clearly interfered with the acid-base profile of calves, especially in oxygenation mechanisms. When calving duration exceeded $4 \mathrm{~h}$, calves had severe hypercapnia and hypoxemia compared with remaining groups, which is due to the longer fetal permanence in the birth canal under a prolonged hypoxemic condition. Kovács et al. (2017) showed that a longer duration of calving leads to acid-base imbalance, regardless of spontaneous or eutocic deliveries. On the other hand, obstetrical assistance improves neonatal oxygenation of calves that are born after $4 \mathrm{~h}$ of calving. Considering remaining circumstances, obstetrical assistance does not impose modifications to the arterial acid-base parameters.

In regards to neonatal arterial blood gas evaluation at birth, we observed altered components of acid-base balance, such as bicarbonate, $\mathrm{BE}, \mathrm{sO}_{2}, \mathrm{pO}_{2}$, and $\mathrm{pCO}_{2}$, without any blood $\mathrm{pH}$ disorders. Even though there were metabolic $(\mathrm{BE})$ and respiratory $\left(\mathrm{pCO}_{2}\right)$ imbalances, the blood buffer system was capable of maintaining $\mathrm{pH}$, regardless of calving duration or obstetrical assistance. In this experiment, the blood buffer bases, such as bicarbonate, were thought to be consumed due to metabolic compensation. Hence, after $120 \mathrm{~min}$, metabolic components of the acid-base balance (bicarbonate and $\mathrm{BE}$ ) were observed to be fully reestablished, as was $\mathrm{pCO}_{2}$. These results show rapid compensation of the acid-base imbalance imposed by calving and, consequently, the optimal prognostics for healthy calves born from eutocia. In fact, upon analyzing the pulmonary mechanic changes of calves, Varga et al. (2001) observed diminished pulmonary resistance and pressure and an increase in pulmonary compliance during the first $6 \mathrm{~h}$ of life. Considering these data, we infer that the compensation for the physiological hypoxia at birth is due to pulmonary functional changes, thus increasing blood oxygenation in the first hours of life, especially during the first $2 \mathrm{~h}$ of life.

In this experiment, all calves had normal rectal temperature, regardless of their obstetrical condition, even in distinct environmental conditions and after the reduction of their rectal temperature at $30 \mathrm{~min}$ of life. Interestingly, calves born after $4 \mathrm{~h}$ of calving had higher rectal temperatures than calves in the remaining groups, especially those under obstetric assistance. This finding may be linked to the increased release of catecholamines during prolonged deliveries and in forced extraction (Chan et al., 1993). In fact, in our study, we detected negative correlations between rectal temperature and $\mathrm{pO}_{2}$ and $\mathrm{sO}_{2}$ in the $>4 \mathrm{~h}$ group, regardless of obstetric assistance. Therefore, the hypoxia derived from prolonged calving resulted in a higher rectal temperature at birth, which might be due to the corresponding release of catecholamines, $\mathrm{ACTH}$, and cortisol. The higher catecholamine production during prolonged calving may be responsible for the increased vascular flow to the brown adipose tissue, and, consequently, for increased heat production (Bellows and Lammoglia, 2000). The higher neonatal stress observed in dystocic calves (Vannucchi et al., 2015c) may corroborate this finding, favoring the organic response to adverse extrauterine conditions. Also, in this study, we observed that obstetric assistance favored thermal maintenance only in prolonged calving ( $>4 \mathrm{~h}$ ).

Serum concentrations of GPx and SOD remained stable from birth to $240 \mathrm{~min}$ of life for calvings that lasted up to $4 \mathrm{~h}$. In contrast, the $>4 \mathrm{~h}$ group showed GPx values that were higher at birth than those of the remaining groups, as well as decreased concentrations at $120 \mathrm{~min}$ of life. It is important to note that serum GPx was negatively correlated with $\mathrm{BE}$, bicarbonate, and $\mathrm{TCO}_{2}$, especially in the $2-4 \mathrm{~h}$ and $>4 \mathrm{~h}$ groups with obstetric assistance. Hence, we suggest that GPx may also participate in the correction of neonatal acidbase imbalance. Davis and Auten (2010) stated that there is a parallel between circulating GPx concentration and fetal pulmonary maturation, which allows for proper ventilation in the hyperoxic extrauterine environment. Therefore, in calves born with assistance after prolonged calving, hypoxia is corrected simultaneously with a local increase in GPx concentration. Moreover, GPx concentration was positively correlated with rectal 
temperature in the $>4 \mathrm{~h}$ group; that is, GPx is thought to take part in neonatal homeostasis. Therefore, GPx is consumed to reach thermoregulation, with a consequent decrease in circulating concentrations.

Interestingly, we observed a positive correlation between GPx and blood glucose concentrations in the $2 \mathrm{~h}$ and $>4 \mathrm{~h}$ groups. In several pathological situations and aging, a spontaneous nonenzymatic reaction (the Maillard reaction) occurs, from which proteins generate glycosylated products (Hipkiss et al., 1998). Malondialdehyde, a product from lipid peroxidation (oxidative stress) reacts with the glycosylated products, generating very toxic substances (Gomezsanchez et al., 1992). Thus, we can infer that changes in glucose concentration during the early neonatal period of calves also affect GPx concentration. Indeed, at birth, both glucose and GPx concentrations were higher than in subsequent periods. Hence, we believe that the antioxidant defense of neonatal calves, represented by GPx, plays a role in the control of the harmful effects of the Maillard reaction. Accordingly, we did not find a correlation between blood glucose and serum TBARS concentrations; that is, the formation of ROS is counteracted through efficient GPx activity.

For calves born under obstetric assistance, we detected increased oxidative stress (TBARS concentration) toward $240 \mathrm{~min}$ of life. Considering spontaneous calving, only calves in the $2-4 \mathrm{~h}$ group had increased oxidative stress over time. Increased oxidative stress was also documented in newborns suffering from acute respiratory distress syndrome (van Zoeren-Grobben et al., 1997). In fact, TBARS concentration was correlated with arterial blood gas variables, indicating an influence of hypoxia on oxidative stress and, consequently, on adaptive vital functions of calves at birth. Therefore, we suggest that obstetric assistance and prolonged calving $(>2 \mathrm{~h})$, along with the relative pulmonary immaturity of neonatal calves, resulted in prolonged hypoxia and greater oxidative stress during the transition period.

In conclusion, obstetric assistance did not favor neonatal vitality or blood oxygenation when calving lasted less than $2 \mathrm{~h}$. Calves that were born after $2 \mathrm{~h}$ of calving had decreased vitality, hypercapnia, hypoxemia, and increased antioxidant status (glutathione peroxidase).

\section{ACKNOWLEDGMENTS}

We thank Fazenda Santa Rita (Agrindus S.A., Descalvado, Brazil), Daniel S. R. Angrimani (School of Veterinary Medicine and Animal Science, University of São Paulo, Brazil), and Marcilio Nichi (School of Veterinary Medicine and Animal Science, University of São Paulo, Brazil) for the statistical analysis and Marcelo Demarchi Goissis (School of Veterinary Medicine and
Animal Science, University of São Paulo, Brazil) for the critical analysis and language revision.

\section{REFERENCES}

Arthur, P. F., J. A. Archer, and G. J. Melville. 2000. Factors influencing dystocia and prediction of dystocia in Angus heifers selected for yearling growth rate. Aust. J. Agric. Res. 51:147-153.

Bellows, R. A., and M. A. Lammoglia. 2000. Effects of severity of dystocia on cold tolerance and serum concentrations of glucose and cortisol in neonatal beef calves. Theriogenology 53:803-813.

Buege, J. A., and S. D. Aust. 1978. Microsomal lipid peroxidation. Methods Enzymol. 52:302-310.

Chan, W. W., F. H. Lonker, W. D. Rausch, and M. A. M. Taverne. 1993. Plasma catecholamines and blood chemistry in newborn calves in relation to different obstetrical procedures and to neonatal outcome. Anim. Reprod. Sci. 34:43-54.

Davis, J. M., and R. L. Auten. 2010. Maturation of the antioxidant system and the effects on preterm birth. Semin. Fetal Neonatal Med. 15:191-195.

Flohé, L., and F. Ötting. 1984. Formation or removal of oxygen radicals. Methods Enzymol. 105:92-104.

Frosali, S., P. Di Simplicio, S. Perrone, D. Di Giuseppe, M. Longini, D. Tanganelli, and G. Buonocore. 2004. Glutathione recycling and antioxidant enzyme activities in erythrocytes of term and preterm newborns at birth. Biol. Neonate 85:188-194.

Gomezsanchez, A., I. Hermosin, and I. Maya. 1992. Synthesis of the Maillard reaction. 2. Influence of malondialdehyde on the Maillard degradation of Amadori compounds. Carbohydr. Res. 229:307-322.

Gunes, V., and G. Atalan. 2006. Comparison of ventral coccygeal arterial and jugular venous blood samples for $\mathrm{pH}, \mathrm{pCO}_{2}, \mathrm{HCO}_{3}$, $\mathrm{Be}(\mathrm{ecf})$ and $\mathrm{ctCO}_{2}$ values in calves with pulmonary diseases. Res. Vet. Sci. 81:148-151.

Herfen, K., and H. Bostedt. 1999. Correlation between clinical and laboratory diagnostic evaluation of the vitality of newborn calves under particular consideration of length and type of parturition. Wien. Tierarztl. Monatsschr. 86:255-261.

Hipkiss, A. R., V. C. Worthington, D. T. J. Himsworth, and W. Herwig. 1998. Protective effects of carnosine against protein modification mediated by malondialdehyde and hypochlorite. Biochim. Biophys. Acta 1380:46-54.

Ilkiw, J. E., R. J. Rose, and I. C. Martin. 1991. A comparison of simultaneously collected arterial, mixed venous, jugular venous and cephalic venous blood samples in the assessment of blood-gas and acid-base status in the dog. J. Vet. Intern. Med. 5:294-298.

Kovács, L., F. L. Kézér, E. Albert, F. Ruff, and O. Szenci. 2017. Seasonal and maternal effects on acid-base, l-lactate, electrolyte, and hematological status of 205 dairy calves born to eutocic dams. J. Dairy Sci. 100:7534-7543.

Kovács, L., F. L. Kézér, and O. Szenci. 2016. Effect of calving process on the outcomes of delivery and postpartum health of dairy cows with unassisted and assisted calvings. J. Dairy Sci. 99:7568-7573.

Mee, J. F. 2011. Bovine neonatal survival-Is improvement possible? Adv. Dairy Technol. 23:161-174.

Mee, J. F., C. Sánchez-Miguel, and M. Doherty. 2014. Influence of modifiable risk factors on the incidence of stillbirth perinatal mortality in dairy cattle. Vet. J. 199:19-23.

Murray, C. F., and K. E. Leslie. 2013. Newborn calf vitality: Risk factors, characteristics, assessment, resulting outcomes and strategies for improvement. Vet. J. 198:322-328.

Murray, C. F., D. M. Veira, A. L. Nadalin, D. M. Haines, M. L. Jackson, D. L. Pearl, and K. E. Leslie. 2015. The effect of dystocia on physiological and behavioral characteristics related to vitality and passive transfer of immunoglobulins in newborn Holstein calves. Can. J. Vet. Res. 79:109-119.

Nagy, O., G. Kovác, H. Seidel, and T. Weissová. 2001. The effect of arterial blood sampling sites on blood gases and acid-base balance parameters in calves. Acta Vet. Hung. 49:331-340.

Nichi, M., I. G. Goovaerts, C. N. Cortada, V. H. Barnabe, J. B. De Clercq, and P. E. Bols. 2007. Roles of lipid peroxidation and cy- 
toplasmic droplets on in vitro fertilization capacity of sperm collected from bovine epididymides stored at 4 and 34 degrees $\mathrm{C}$. Theriogenology 67:334-340.

Norén, H., I. Amer-Wahlin, H. Hagberg, A. Herbst, I. Kjellmer, K. Marsal, P. Olofsson, and K. G. Rosen. 2003. Fetal electrocardiography in labor and neonatal outcome: Data from the Swedish randomized controlled trial on intrapartum fetal monitoring. Am. J. Obstet. Gynecol. 188:183-192.

Ohkawa, H., N. Ohishi, and K. Yagi. 1979. Assay for lipid peroxides in animal tissues by thiobarbituric acid reaction. Anal. Biochem. 95:351-358.

Patterson, D. J., R. A. Bellows, P. J. Burfening, and J. B. Carr. 1987. Occurrence of neonatal and postnatal mortality in range beef cattle. I. Calf loss incidence from birth to weaning, backward and breech presentation and effects of calf loss on subsequent pregnancy rate of dams. Theriogenology 28:557-571.

Rice, L. E. 1994. Dystocia-related risk factors. Vet. Clin. North Am. Food Anim. Pract. 10:53-68.

Riley, D. G., C. C. Chase, T. A. Olson, S. W. Coleman, and A. C. Hammond. 2004. Genetic and nongenetic influences on vigor at birth and preweaning mortality of purebred and high percentage Brahman calves. J. Anim. Sci. 82:1581-1588.

Schafer, S., and K. Arbeiter. 1995. Relations between parturition, vitality and some blood parameters of the neonatal calf. Wien. Tierarztl. Monatsschr. 82:271-275.

Schuenemann, G. M., I. Nieto, S. Bas, K. N. Galvão, and J. Workman. 2011. Assessment of calving progress and reference times for obstetric intervention during dystocia in Holstein dairy cows. J. Dairy Sci. 94:5494-5501.

Siristatidis, C., E. Salamalekis, D. Kassanos, C. Loghis, and G. Creatsas. 2004. Evaluation of fetal intrapartum hypoxia by middle cerebral and umbilical artery Doppler velocimetry with simultaneous cardiotocography and pulse oximetry. Arch. Gynecol. Obstet. 270:265-270

Uystepruyst, C., J. Coghe, T. H. Dorts, N. Harmegnies, M. H. Delsemme, T. Art, and P. Lekeux. 2002. Effect of three resuscitation procedures on respiratory and metabolic adaptation to extra uterine life in newborn calves. Vet. J. 163:30-44.

van Zoeren-Grobben, D., J. H. N. Lindeman, E. Houdkamp, R. M. W. Moison, J. T. Wijnen, and H. M. Berger. 1997. Markers of oxidative stress and antioxidant activity in plasma and erythrocytes in neonatal respiratory distress syndrome. Acta Paediatr. 86:1356-1362.

Vannucchi, C. I., D. Kishi, F. M. Regazzi, L. Silva, G. Veiga, D. Angrimani, C. F. Lucio, and M. Nichi. 2015a. The oxidative stress, antioxidant profile and acid-base status in preterm and term canine neonates. Reprod. Domest. Anim. 50:240-246.

Vannucchi, C. I., J. A. Rodrigues, L. C. Silva, C. F. Lúcio, and G. A. Veiga. 2015b. Effect of dystocia and treatment with oxytocin on neonatal calf vitality and acid-base, electrolyte and haematological status. Vet. J. 203:228-232.

Vannucchi, C. I., J. A. Rodrigues, L. C. Silva, C. F. Lúcio, G. A Veiga, P. V. Furtado, C. A. Oliveira, and M. Nichi. 2015c. Association between birth conditions and glucose and cortisol profiles of periparturient dairy cows and neonatal calves. Vet. Rec. 176:358.

Vannucchi, C. I., L. C. G. Silva, S. M. Unruh, C. F. Lúcio, and G. A L. Veiga. 2018. Calving duration and obstetric assistance influence pulmonary function of Holstein calves during immediate fetal-toneonatal transition. PLoS One 13:e204129.

Vannucchi, C. I., L. G. Silva, C. F. Lúcio, and G. A. Veiga. 2017 Influence of the duration of calving and obstetric assistance on the placental retention index in Holstein dairy cows. Anim. Sci. J. 88:451-455.

Varga, J., L. Mester, L. Börzsönyi, P. Lekeux, and O. Szenci. 2001 Improved pulmonary adaptation in newborn calves with postnatal acidosis. Vet. J. 162:226-232.

Yamamoto, Y., and K. Takahashi. 1993. Glutathione peroxidase isolated from plasma reduces phospholipid hydroperoxides. Arch. Biochem. Biophys. 305:541-545. 